\title{
Psychobiosocial states in competitive badminton: Similarities and differences between juniors, adolescents and adults
}

\author{
Yun-Dih Chia-Smith' \\ ' Loyola University Maryland, Baltimore, Maryland, USA
}

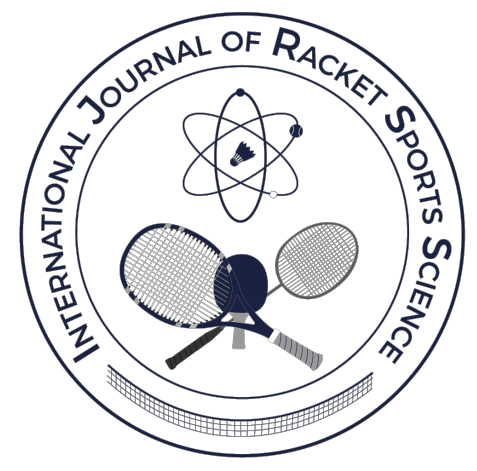

\begin{abstract}
Emotions affect the way elite athletes respond during competitive play. Elite athletes who identify and regulate emotions can increase their consistency and optimize high quality play. This cross-sectional study examined the extent to which psychobiosocial states of elite badminton players vary by age. Ninety-one elite badminton players in three age groups (lower juniors, upper juniors, and adults) rated their post-play perceptions on eight components of psychobiosocial states (Bortoli, et al., 2008) for both their best and worst performance during the tournament. Descriptive statistics assessed the relative strength of emotions on each item and an analysis of variance examined differences between the three groups. Age differences were found in the perception of the psychobiosocial states in competitive badminton matches in terms of most identified states and intensity. The findings inform coaches' understanding athlete's individual zone of optimal function (IZOF) and can help them cope with psychobiosocial states during matches.
\end{abstract}

Keywords: Psychobiosocial States, Developmental, Age Differences, Juniors, Badminton

Correspondence author: Yun-Dih Chia-Smith

E-mail: ychiasmith@loyola.edu

Cite this article as:

Chia-Smith, Y. (2019). Psychobiosocial states in competitive badminton: Similarities and differences between juniors, adolescents and adults. International Journal of Racket Sports Science, 1(2), 49-60. 


\section{Literature review}

Emotion plays a significant role in athletic competitions, particularly for elite athletes (Deci, 1980). Performance in competitive settings is not only a product of long training sessions, natural proclivities but also influenced by split-second responses of mental status. For the past three decades, sports psychologists have explored relationships between anxiety and performance, emotions and performance. More recently, the relationship between multiple components has emerged under a single concept; psychobiosocial states: Emotion, motivation, bodily reaction, operation, communication, volition, motor behaviour and cognition (Bortoli, Bertollo \& Robazza 2009). At the same time, there are developmental differences in all of these psychobiosocial states. Splitsecond mental reactions influenced by the psychobiosocial states. However, the effect and interaction within and among the states depend on the development of the athlete, typically in age ranges. For example, junior athletes are more likely to perceive and react differently from their adult counterparts.

\section{Psychobiosocial states}

In 2000, Hanin defined the Individual Zone of Optimal Function (IZOF) as "a focus on describing, predicting, explaining, and regulating performancerelated psychobiosocial states affecting individual and team activity" (p.66). The eight psychobiosocial states can be both positive or negative and can have the optimal or dysfunctional influence on performance. The key factor is the relative intensity that the athlete experiences in Psychobiosocial states that creates a personalized IZOF. Understanding players IZOF can modulate performance, predict future performance, and support coaches as they train players to identify and regulate components in future performance. If coaches and players can better regulate mental status, it is hypothesized that they can improve their performance. Failure to regulate mental status can result in persistent under-performance in highly competitive matches. Based on the underpinnings of IZOF profiles (Hanin, 2000; Hanin \& Ekkikakis, 2014), researchers developed a standardized tool to assess athletes' states during competitions. Eight psychobiosocial states are contributing to athletes' performances in various sports contexts: cognitive, emotional, motivational, operational, bodily, volitional, motor behavioural, and communicative (Bortoli, Bertollo, \& Robazza, 2009; Bortoli, Bertollo, Comani, \& Robazza, 2011; Robazza, Bertollo, Ruiz, \& Bortoli, 2016).

\section{Developmental differences in 8 psychobiosocial states}

The impact of psychobiosocial-performance happens in real time and can change in a matter of seconds during competition. For athletes to effectively regulate their multiple states, they have to quickly identify the states they are trying to regulate. This ability differs by age and by psychobiosocial component. A brief description of the 8 states demonstrates that each are important and influential in the heat of close competitive play, reaction of a perceived bad call by an official, or poor execution on a routine action.

\section{Cognition}

Children and adolescent's attention spans and strategies used to reason and make sense of the world differ from adults. They move from very concrete thinking toward abstract thinking, and eventually, most adults proceed toward more dialectic thinking strategies. These differences are partially explained by the unique ways in which the different developmental groups process various stimuli presenting to them. With more advanced stages of cognitive development, older adolescents exhibit more efficient strategies compared to their younger counterparts in multiple sports competition settings (Micklewright et al., 2012; French \& McPherson, 1999).

\section{Emotion}

Emotional changes experienced in childhood generally differs from emotions in adolescence and adulthood. As children get older and have more experiences to deal with, they can make a more effective prediction of how they will react when the environment provides a stimulus (Barrett, 2017). A longitudinal study of football (soccer) players found that the emotional, interactive process of "reaction and 
regulation" differed between adolescents and either children or adults (Piero, Saxbe, \& Margolin 2016). Older adolescent athletes showed more effective coping stressors skills than younger players (Reeves, Nicholls and Mckenna, 2009). Neuroscientists suggest that brain structures play an essential role in human emotions. Brain regions, the amygdala, and the prefrontal cortex contribute to human emotion perception and regulation. an intense, fast pace rally (stimuli) might be emotionally perceived stronger to the adolescent than to the children and to the adults (Zald, 2003).

\section{Motivation}

Several motivation theories have been examined in a variety of sports contexts including Harter's competence motivation theory to Coaching style. Each demonstrates influence on athletes' perception of their ability and subsequently their motivation to perform. Coaching with mastery goals in mind predicts greater ability perception, motivation, and fun (Weiss, Amorose, \& Wilko, 2009). Social status was shown as a more important motivation factor for adolescents than children and adults. Also, there are health/fitness differences between age groups (Brodkin \& Weiss, 1990), with younger athletes valuing coaches/parents' opinions more than adolescents and adults.

\section{Motor behaviour}

Speed, agility, explosive strength, shoulder strength, and muscular endurance are the most critical five motor components in badminton performance (Tiwarl, Rai, \& Srinet, 2011). Players in different age group exhibit different motor abilities due to physical development. Therefore some levels of performance are correlated to physical development status (Filipcic, Pisk, \& Filipcic, 2010). Physical training and repetitive actions can influence footwork and reaction times, but structural motor behaviour is limited by natural aging.

\section{Volition}

Zimmerman's cyclical phases model of selfregulation learning examine the relationship between performance, motivation and strategy selection (Zimmerman, 2000). The model and its interactions have been shown to exist in both classroom and sports contexts (Cleary \& Zimmerman, 2001; Zimmerman, 1998). Experienced athletes exhibit higher levels of self-regulation. They organize skills more efficiently, exhibit better recall, and are more accurate in anticipating stimuli (Starkes et al. 1994; McPherson, 1993). A longitudinal study showed that that gaining experience in sports contexts presented better selfregulation in emotion controls in other aspects of life (Oaten and Cheng, 2006).

\section{Bodily}

Physical differences play a significant role in sports performances. Height, body mass, aerobic power, muscular strength, endurance, and speed provide performance advantages in most sports (Malina, Bouchard, \& Bar-Or 2004), including badminton. A year of maturation, especially during puberty, can be associated with performance differences (Cobley, Baker, Wattie, \& McKenna, 2009). Between the ages of 12 to adulthood, male players can grow as much as 90 $\mathrm{cm}$ and gain 7-30 kg. Body mass and body fat level dramatically changed from pre-teen to adulthood years (Chahar, 2014; Stang \& Story, 2005).

\section{Operations}

Badminton involves a high volume of cognitive exchanges, rapid problem solving, and instant crisis identification. Atkinson and Shiffrin (1968) created a model to link information processes to memory, which was known as 'The multi-store model and memory'. This model describes memory in terms of the information flows through a system. Age was a strong predictor in memory recall during the performance. Research shows that CMP increases with increased age. (Hicheur et al., 2017; Touron \& Hertzog, 2004).

This study examined the intensity of 8 psychobiosocial states in elite badminton players and tested the extent to which the states differed by age range. Based on the literature, it was hypothesized that there would be age differences in the 8 states.

\section{Research questions}


1. Which psychobiosocial states are most intense during player's recall of their best and worst badminton performance?

2. Are there significant differences in badminton players' psychobiosocial states by age range?

\section{Method}

Participants
The sample for the study included ninety-one high performing male athletes who participated in the USA Badminton (USAB) sanctioned tournaments during the 2017 season. The sample consisted of thirty juniors between the ages of 10 to 12 (Mean $=11.36, \mathrm{SD}=.66)$; thirty late adolescents between the ages of 16 to 19 (Mean $=16.9, \mathrm{SD}=.84)$; thirty-one adults between the ages of 23 to 45 (Mean=32.5, SD=7.93). Table 1 presents the ages, years of competition, and the selfreported days/week training per year.

Table 1.

Age, years of competition, and average practice per week

\begin{tabular}{lcccccc}
\hline & \multicolumn{2}{c}{$\begin{array}{c}\text { Junior } \\
(\mathbf{n}=30)\end{array}$} & \multicolumn{2}{c}{$\begin{array}{c}\text { Adolescent } \\
(\mathbf{n}=30)\end{array}$} & \multicolumn{2}{c}{$\begin{array}{c}\text { Adults } \\
(\mathbf{n}=31)\end{array}$} \\
\hline Mean & SD & Mean & SD & Mean & SD \\
\hline Age & 11.36 & 0.66 & 16.9 & 0.84 & 32.50 & 7.93 \\
Years of Competition & 3.4 & 1.40 & 6.48 & 2.14 & 14.96 & 5.95 \\
Training Per Week (Times) & 4.24 & 2.4 & 3.65 & 1.49 & 3.72 & 1.80 \\
\hline
\end{tabular}

\section{Measures}

The PBS-ST Scale is an assessment of measuring athlete's psychobiosocial state (Robazza, Bertollo, Ruiz, \& Bortoli, 2016). The PBS-ST Scale (Bortoli \& Robazza, 2008, 2011) contains functional and dysfunctional descriptors of competitive play and has been used in prior studies with several types of sports. Each psychobiosocial State (PBS-ST) includes two or three descriptors. Items include: Emotional (affective functional, emotional-affective dysfunctional, anxiety functional, anxiety dysfunctional, anger functional, anger dysfunctional), Cognitive (functional, dysfunctional), Motor behaviour (functional, dysfunctional), Motivational (functional, dysfunctional), Volitional (functional, dysfunctional), Operational (functional, dysfunctional), Bodily (functional, dysfunctional), and Communication (functional, dysfunctional). The items were randomly ordered. The participants were asked to respond to each PBS-ST on a 5-point Likert scale, ranging from zero (not at all) to four (very much). Intensity ratings were selected on the following criteria: $0=$ nothing at all, $1=$ very little, 2 =moderate, 3 = much, 4 = very much. This resulted in each athlete identifying specific functional and dysfunctional content (descriptors) related to each of the 8 performance states and ratings of their intensity. A total PBS-ST score was created by summing across all. Two studies conducted by Robazza et al. (2016) reported evidence for internal validity and construct validity of the instrument.

\section{Procedure}

There were two phases in the implementation of measures for this study. First, Loyola University Maryland Institutional Review Board (IRB) reviewed the proposal and assessed the rights and protections of the participants, especially there are minors involved in this study. Second, the instrument was administered to the participants in various tournaments in the U.S. during the 2017-2018 season. Next, the survey was administrated to athletes between October 2017 to July 2018. The primary investigator (PI) collected the player lists before major USAB sanctioned tournaments. The PI provided a brief introduction to qualified participants 
at the beginning of the tournament. The introduction included a description of the purpose of the study and the rights of participants. Athletes who agreed to complete the study indicated their consent to participate. Both parents and players under the age of 18 signed consent and assent forms respectively. Each participant responded to both their best performance in a single match and worst performance in a single match at the end of the respective tournament. There was no time limit to complete the survey and the time to complete varied between 10- $25 \mathrm{~min}$. Participants received two racket grips as a reward for participation in the study.

\section{Data analysis}

Mean scores on each item were calculated for the three age groups. One-way ANOVAs were performed to examine any statistically significant mean differences in PBS-STs for each age group and to determine the relative impact of particular states on best and worst performance across age groups.

\section{Results}

The result of the analysis show that players at all levels rated functional states more highly than dysfunction states during their best performance. Conversely dysfunctional states were rated highly for the worst performance. This is an intuitive finding that while some consistency emerged, there were variations by age categories. The five most highly rated states for junior athletes during their best performances included motor behaviour functional, volitional functional, bodily functional, cognitive functional and motivational functional (See Table 2). The five highest rated states for adolescents were bodily functional, cognitive functional, emotional anger functional, volitional functional, and motivational functional. The five for adults were cognitive functional, motivational functional, emotional affection functional, volitional functional, and bodily functional. On the worst performance, junior athletes rated bodily dysfunctional, operational dysfunctional, motor behavioural dysfunctional, emotional anxiety functional and emotional anger dysfunctional. The five most chosen states for adolescents during were emotional anger dysfunctional, cognitive dysfunctional, motor behavioural dysfunctional, operational dysfunctional, and bodily dysfunctional. For adults the five highest rated states included emotional anxiety functional, cognitive dysfunctional motor behavioural dysfunctional, operational dysfunctional, and bodily dysfunctional.

Table 2.

Five psychobiosocial states during performances - by age $(M=$ mean; $S D=$ standard deviation)

\begin{tabular}{|c|c|c|c|c|c|}
\hline \multicolumn{2}{|c|}{ Juniors } & \multicolumn{2}{|c|}{ Adolescents } & \multicolumn{2}{|c|}{ Adults } \\
\hline $\begin{array}{c}\text { Best } \\
\text { Performance }\end{array}$ & $\begin{array}{c}\text { Worst } \\
\text { Performance } \\
\end{array}$ & $\begin{array}{c}\text { Best } \\
\text { Performance }\end{array}$ & $\begin{array}{c}\text { Worst } \\
\text { Performance }\end{array}$ & $\begin{array}{c}\text { Best } \\
\text { Performance } \\
\end{array}$ & $\begin{array}{c}\text { Worst } \\
\text { Performance }\end{array}$ \\
\hline $\begin{array}{l}\text { Motor behavioral } \\
\text { functional } \\
(\mathrm{M}=3.50 \\
\mathrm{SD}=.68)\end{array}$ & $\begin{array}{l}\text { Bodily } \\
\text { dysfunctional } \\
(M=3.06 \\
S D=1.14)\end{array}$ & $\begin{array}{l}\text { Bodily functional } \\
(\mathrm{M}=3.63 \\
\mathrm{SD}=.49)\end{array}$ & $\begin{array}{l}\text { Emotional anger } \\
\text { dysfunctional } \\
(\mathrm{M}=3.1 \\
\mathrm{SD}=1.01)\end{array}$ & $\begin{array}{l}\text { Cognitive } \\
\text { functional } \\
(\mathrm{M}=3.41, \\
\mathrm{Sd}=.67)\end{array}$ & $\begin{array}{l}\text { Emotional } \\
\text { anxiety } \\
\text { functional } \\
(\mathrm{M}=3.09 \\
\mathrm{SD}=1.01)\end{array}$ \\
\hline $\begin{array}{l}\text { Volitional } \\
\text { functional } \\
(\mathrm{M}=3.43 \text {, } \\
\mathrm{SD}=.57)\end{array}$ & $\begin{array}{l}\text { Operational } \\
\text { dysfunctional } \\
(M=3.06 \\
S D=.94)\end{array}$ & $\begin{array}{l}\text { Cognitive } \\
\text { functional } \\
(\mathrm{M}=3.56 \\
\mathrm{SD}=.50)\end{array}$ & $\begin{array}{l}\text { Cognitive } \\
\text { dysfunctional } \\
(\mathrm{M}=3.03 \\
\mathrm{SD}=.808)\end{array}$ & $\begin{array}{l}\text { Motivation } \\
\text { functional } \\
(\mathrm{M}=3.32 \\
\mathrm{SD}=.65)\end{array}$ & $\begin{array}{l}\text { Cognitive } \\
\text { dysfunctional } \\
(M=3.03 \\
S D=.87)\end{array}$ \\
\hline
\end{tabular}




\begin{tabular}{|c|c|c|c|c|c|}
\hline $\begin{array}{l}\text { Bodily functional } \\
(\mathrm{M}=3.40 \\
\mathrm{SD}=.72)\end{array}$ & $\begin{array}{l}\text { Motor } \\
\text { behavioural } \\
\text { dysfunctional } \\
(\mathrm{M}=3.06 \\
\mathrm{SD}=1.01)\end{array}$ & $\begin{array}{l}\text { Emotional } \\
\text { Anger functional } \\
(\mathrm{M}=3.55 \\
\mathrm{SD}=.57)\end{array}$ & $\begin{array}{l}\text { Motor } \\
\text { behavioural } \\
\text { dysfunctional } \\
(\mathrm{M}=2.93 \\
\mathrm{SD}=1.11)\end{array}$ & $\begin{array}{l}\text { Emotional } \\
\text { Affection } \\
\text { functional } \\
(\mathrm{M}=3.32 \\
\mathrm{SD}=.72)\end{array}$ & $\begin{array}{l}\text { Motor } \\
\text { behavioural } \\
\text { dysfunctional } \\
(\mathrm{M}=2.93 \text {, } \\
\mathrm{SD}=.99)\end{array}$ \\
\hline $\begin{array}{l}\text { Cognitive } \\
\text { functional } \\
(\mathrm{M}=3.23 \\
\mathrm{SD}=.77)\end{array}$ & $\begin{array}{l}\text { Emotional } \\
\text { anxiety } \\
\text { functional } \\
(\mathrm{M}=2.87, \\
\mathrm{SD}=1.04)\end{array}$ & $\begin{array}{l}\text { Volitional } \\
\text { functional } \\
(M=3.26 \\
S D=1.04)\end{array}$ & $\begin{array}{l}\text { Operational } \\
\text { dysfunctional } \\
(\mathrm{M}=2.86 \\
\mathrm{Sd}=1.07)\end{array}$ & $\begin{array}{l}\text { Volitional } \\
\text { functional } \\
(M=3.29 \\
S D=.78)\end{array}$ & $\begin{array}{l}\text { Operational } \\
\text { dysfunctional } \\
(\mathrm{M}=2.84 \\
\mathrm{Sd}=.87)\end{array}$ \\
\hline $\begin{array}{l}\text { Motivational } \\
\text { functional } \\
(\mathrm{M}=3.23 \\
\mathrm{SD}=.77)\end{array}$ & $\begin{array}{l}\text { Emotional } \\
\text { Anger } \\
\text { dysfunctional } \\
(\mathrm{M}=2.80 \\
\mathrm{SD}=1.18)\end{array}$ & $\begin{array}{l}\text { Motivational } \\
\text { functional } \\
(M=3.13 \\
S D=1.10)\end{array}$ & $\begin{array}{l}\text { Bodily } \\
\text { dysfunctional } \\
(M=2.72 \\
S D=1.16)\end{array}$ & $\begin{array}{l}\text { Bodily } \\
\text { functional } \\
(M=3.22 \text {, } \\
S D=.99)\end{array}$ & $\begin{array}{l}\text { Bodily } \\
\text { dysfunctional } \\
(\mathrm{M}=2.58 \\
\mathrm{SD}=1.31)\end{array}$ \\
\hline
\end{tabular}

The analysis found significant differences among the three age groups in their PBS-ST total score during their best performance $(\mathrm{F}(2,86)=5.6$, $\mathrm{p}<.01)$. Table 3 shows that juniors experienced higher intensity of their psychobiosocial states during their best performance than their adolescent and adult counterparts. Differences between juniors/adolescents and junior/adults $(p<.01)$ were statistically significant. However the differences between adolescents and adults' PBS-ST in their best performance were not statistically significant. Additionally there were no statistically significant differences in PBS-ST total score on self-reported worst performance.

Table 3.

Age differences in PBS-ST total score by performances

\begin{tabular}{lllcc}
\hline \multirow{2}{*}{ Best performance } & N & Mean & Standard deviation \\
& Juniors** $^{*}$ & 30 & 42.63 & 8.15 \\
& Adolescents & 28 & 38.85 & 6.53 \\
& Adults & 31 & 35.74 & 5.42 \\
Worst performance & & & & \\
& Juniors & 30 & 36.90 & 4.41 \\
& Adolescents & 28 & 34.42 & 7.21 \\
& Adults & 26 & 35.42 & 6.54 \\
\hline
\end{tabular}

Note: ${ }^{* *} \mathrm{p}<.01$

ANOVA was performed to examine each state impact on performances across each group. There were age significant differences in 9 states including emotional anger functional $(\mathrm{F}=3.23, \mathrm{p}=.044)$, cognitive dysfunctional $(\mathrm{F}=4.37, \mathrm{p}=.015)$, communicative dysfunctional $(\mathrm{F}=6.17, \mathrm{p}=.003)$, emotional anxiety functional $(\mathrm{F}=5.02, \mathrm{p}=.009)$, motor behavioural dysfunctional $(\mathrm{F}=15.79, \mathrm{p}=.000)$, motivational dysfunctional $(\mathrm{F}=15.36, \mathrm{p}=.000)$, emotional anxiety dysfunctional $(\mathrm{F}=8.87, \mathrm{p}=.000)$. emotional anger dysfunctional $\quad(\mathrm{F}=8.49, \quad \mathrm{p}=.000), \quad$ volitional dysfunctional $(\mathrm{F}=4.9, \mathrm{p}=.009)$. Table 4 shows the 
means, standard deviations, significant difference

between juniors, adolescents and adults by state.

Table 4.

Age differences on psychobiosocial status

\section{Best Performance}

PBS-ST

Emotional Anger Functional *

Emotional Anxiety Functional **

Emotional Anger Dysfunctional **

Emotional Anxiety Dysfunctional **

Cognitive Dysfunctional *

Communicative Dysfunctional **

Motor Behavioural Dysfunctional **

Motivational Dysfunctional **

Volitional Dysfunctional **
Junior

$$
\text { Mean }
$$

1.46

0.80

1.73

1.06

0.93

1.13

0.63

0.73

1.6

.93

1.36

2.80
SD

1.06

1.45

0.80

1.63

1.12

0.98

0.77

0.66

1.14
Adolescent

Mean

3.55

0.57

1.17

1.33

0.72

0.94

0.81

0.37

0.25

0.30
Adults

Mean SD

$3.19 \quad 0.94$

$0.51 \quad 0.81$

$0.38 \quad 0.76$

$0.67 \quad 0.94$

$0.61 \quad 0.11$

$0.22 \quad 0.08$

$0.38 \quad 0.84$

$0.09 \quad 0.30$

$0.32 \quad 0.70$

\section{$\underline{\text { Worst Performance }}$}

Cognitive function $* *$

Communicative function*

Volitional function **

Emotional anger dysfunctional ${ }^{* *}$
.93

.82

.92

1.18
.60

.42

.57

3.10
.78

.69

.87

1.03
1.07

1.0

1.23

1.76
.84

.86

1.17

Note: ${ }^{*} \mathrm{p}<.05 ;{ }^{* *} \mathrm{p}<.01$

Although there are age differences found in 9 PBSSTs, the distributions are not consistent. Most of the differences are found in between juniors/adolescents and junior/adults. Juniors and adolescents report significantly different scores on emotional anger functional and volitional dysfunctional during their perceived best performance. Juniors stated stronger feelings toward cognitive dysfunctional, communicative dysfunctional, emotional anxiety functional, and emotional anger dysfunctional when compared with adult players. Juniors reported higher intensity toward motor behavioural dysfunctional, and motivational dysfunctional when compared to both adolescents and adults. Overall, juniors experienced stronger dysfunctional states during their best performance than adolescents and adults (See Figure 2). 


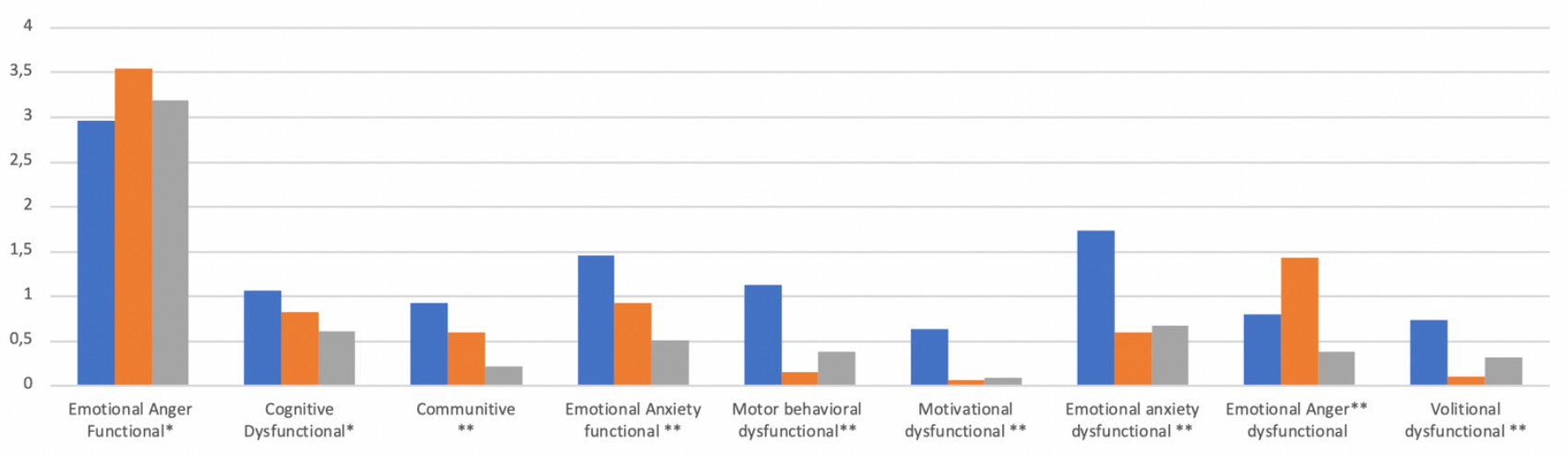

- Juniors $\quad$ - Adolescents $\quad$ Adults

Figure 2. Differences of psychobiosocial states by age according to their best performance.

While there were no overall differences during worst performance, some differences emerged by functional component. For example, there were significant differences in cognitive functional, communicative functional, volitional functional, and emotional anger dysfunctional. Figure 3 shows higher levels of intensity in cognitive functional and volitional functional in juniors compared to adolescents, but no differences when compared to adults. Adolescents and adults felt differently in communicative functional and volitional functional. Compared to their adult counterparts, juniors and adolescents reported stronger feeling in emotional anger dysfunctional during their perceived worst performance.

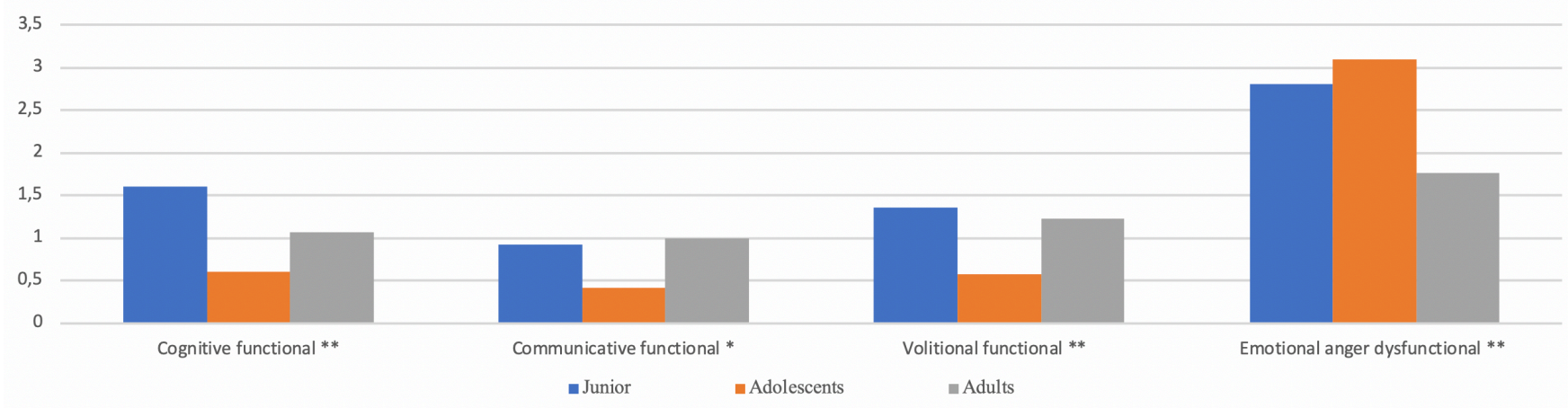

Figure 3. Differences on psychobiosocial states by age according to their worst performance

\section{Discussion}

The purpose of this study was to identify the intensity of psychobiosocial states in competitive badminton players' self-reported best and worst performance at USAB sanctioned tournament. The study also examined the extent to which development, as defined by age group, impacts athletes' perceptions of play. The results confirmed previous studies showing that emotion affects performance in competitive sports. While this comes as no surprise to those who compete in competitive sports, the study provides a deeper, more nuanced understanding of eight psychobiosocial states. The eight psychobiosocial states (cognitive, emotional, motivational, bodily, communication, operational, motor behavioural and volitional), and athlete's 
ability to identify and regulate them influence player's perceived quality of performance. The crosssectional study showed differences by age range on the total scale score as well as within and between various components. Adult participants reported higher intensity of cognitive and emotional state during both their best and worst performance. Juniors' consistently perceived stronger intensity in physical actions (bodily and motor behavioural) during both best and worst performance. During their worst performance, physical and negative emotional anxiety dominated juniors' states. They were less likely to focus on cognition functions such as information processing and strategic planning. The findings echo the classic Piaget's theory stages of cognitive development that suggests that children under 12 in the stage of concrete operational experiences with the environment focus on what they see in front of them. Adolescents, especially older adolescents, and adults entering higher levels of cognition possess the ability to think more abstractly. This was consistent with their intensity on more cognitive than physical reactions. Unlike their junior and adult counterparts, a unique emotion emerged in adolescents. Adolescent emotions were more consistent with anger rather than anxiety/affection in both best and worst performances. Anger was presented as both facilitator and inhibitor during the competitions. Besides the dysfunctional emotion anger, adolescent and adult participants experienced very similar psychobiosocial states during their worst performance.

During their best performance, junior participants experienced significantly more intense, higher overall total scores. Compared with juniors, later adolescents were similar to adults in their cognitive, emotional and physical states. The intensity of states was more pronounced in juniors, with higher mean scores on 8 out of 20 states as compared to their adults and adolescent counterparts. Adult and adolescent did not experience as many dysfunctional states as junior participants. The one exception was in the emotional anger function. Adolescents counted on the emotional anger, such as fighting, spirit, fierce, aggressive, to facilitate their performance more than juniors and adults reported. Adolescent's perception of the matches, especially the perception of emotional anger, echoed Stanly Hall (1904) characterized adolescents as a time of "storm and strife". Anger presented as drive and damage to adolescents' performance (Arnett, 2006). When compared to adolescents and adults, juniors experienced a higher level of anxiety (both functional or dysfunctional) during their best performance. This is most likely associated with their lack of experiences or immaterial brain development, causing inaccurate evaluation during intensive competition. The uncertainty produces elevated anxiety during the match. It is reasonable to find a higher anxiety level in juniors than in adolescents and adults, especially in the winning condition.

When evaluating their worst performance, participants' overall psychobiosocial states were similar across all age groups. Adolescents presented less intensive mental states compared to juniors and adults participants in cognitive, communication, and volition. Negative emotional anger was found in juniors and adolescents mental states, but this had less impact on adults' performance. Some similarities across age groups were found, primarily in their reflection on their worst performances. They all reported experiencing negative physical reactions. Secondly, drive (motivation and volition) were in the top 5 states in their best performances. Third, the top 5 states reported in best performances were functional, while the top 5 states in worst performances were dysfunctional. This finding echoed the ZOF model, where positive states facilitate the performances, and negative states work against athlete's performance.

\section{Implications for theory and practice}

The findings from this study have theoretical implications from both ZOF model and developmental psychology. Not all psychobiosocial states were perceived similarly across all age players. Future longitudinal studies could examine if developmental differences emerge in a set of players as the progress from juniors to adolescents to adults in competitive badminton. To promote the most 
optimal results during a match in a split second, coaches need to understand that players of different ages perceive and experience various psychobiosocial states differently during matches. With unique physical, cognitive and psychosocial developmental status, a player experiences three distinguished stages within their own growth. Coaches who are sensitive to limitations of regulating particular states can discuss how the player is reacting in real time to a particular drill or practice match. The conversation can help the player articulate their psychobiosocial state, in their own words, and the coach can help them with strategies to identify and react the next time the player feels a similar way. They can create signs and talking points that can translate to how to coach during competitive badminton matches. This is particularly salient when players express anger. During the interval, coaches can refocus the player and give them reminders of how to regulate the feelings during the next several points. Additionally, after matches, players can reflect on how they reacted to various states during the match. To move in this direction, additional professional development for coaches psychobiosocial states can be incorporated into coach credentialing.

\section{Acknowledgements}

This research is sponsored by Badminton World Federation

\section{References}

Atkinson, R.C., \& Shiffrin, R.M. (1968). "Chapter: Human memory: A proposed system and its control processes". In Spence, K.W.; Spence, J.T. The psychology of learning and motivation. New York: Academic Press. pp. 89-195.

Arnett, J. J. (2006). G. Stanley Hall's Adolescence: Brilliance and nonsense. History of Psychology, 9(3), 186-197. Doi:10.1037/1093-4510.9.3.186

Bandura, A. (1995). Social foundations of thought and action: A social cognitive theory. Englewood Cliffs, NJ: Prenctice Hall.

Barrett, L. F. (2017). The theory of constructed emotion: An active inference account of interoception and categorization. Social Cognitive and Affective Neuroscience, 12(11), 1833-1833. Doi:10.1093/scan/nsx060

Bortoli L, Bertollo M, Comani S, \& Robazza C. (2011). Competence, achievement goals, motivational climate, and pleasant psychobiosocial states in youth sport. J Sports Sci, 29, 171-80. Doi: 10.1080/02640414.2010.530675

Bortoli, L., Bertollo, M., Filho, E., \& Robazza, C. (2013). Do psychobiosocial states mediate the relationship between perceived motivational climate and individual motivation in youngsters? Journal of Sports Sciences, 32(6), 572-582. Doi:10.1080/ 02640414.2013 .84301

Bortoli, L., Bertollo, M., \& Robazza, C. (2009). Dispositional goal orientations, motivational climate, and psychobiosocial states in youth sport. Personality and Individual Differences, 47(1), 18-24. Doi:10.1016/j.paid.2009.01.042

Brodkin, P., \& Weiss, M. R. (1990). Developmental Differences in Motivation for Participating in Competitive Swimming. Journal of Sport and Exercise Psychology, 12(3), 248-263. Doi:10.1123/jsep.12.3.248

Chahar P. S.(2014). Physiological basis of Growth and Development among Children and Adolescent in Relation to Physical Activity. American Journal of Sports Science and Medicine. 2:17-22. Doi: 10.12691/ajssm-2-5A-5.

Cleary, T. J., \& Zimmerman, B. J. (2001). SelfRegulation Differences during Athletic Practice by Experts, Non-Experts, and Novices. Journal of Applied Sport Psychology, 13(2), 185-206. Doi:10.1080/104132001753149883

Cobley, S., Baker, J., Wattie, N., \& McKenna, J. (2012, October 07). Annual Age-Grouping and Athlete Development. Retrieved October 15, 2018, from

https://link.springer.com/article/10.2165/0000725 6-200939030-00005

Deci, E. (1980). The psychology of self-determination. Lexington, MA: DD Heath

Filipcic, A., Pisk. L., and Filipcic,T. (2010) Relationship between the results of selected motor 
tests and competitive successfulness in tennis for different age categories, Kinesiology, 42, 175-183.

French, K. E., \& McPherson, S. L. (2004). Development of expertise in sport. In M. R. Weiss (Ed.), Developmental sport and exercise psychology: $A$ lifespan perspective (pp. 403-423). Morgantown, WV: Fitness Information Technology

Hanin, N. L. (2000). Emotions in sport. Champaign, IL: Human Kinetics.

Hanin J, Ekkekakis P. Emotions in sport and exercise settings. In: Papaioannou AG, Hackfort D, editors. Routledge companion to sport and exercise psychology: global perspectives and fundamental concepts. New York, NY: Routledge; 2014. p. 83104.

Hicheur, H., Chauvin, A., Chassot, S., Chenevière, X., \& Taube, W. (2017). Effects of age on the soccerspecific cognitive-motor performance of elite young soccer players: Comparison between objective measurements and coaches' evaluation. Plos One, 12(9). Doi:10.1371/journal.pone.0185460

Kail, R. \& Bisanz, J. (1982). Information Processing and Cognitive Development. Advances in Child Development and Behavior. 17, 45-81. https://Doi.org/10.1016/S0065-2407(08)60357-2

Malina, R. M., Bouchard, C., \& Bar-Or, O. (2004). Growth, maturation, and physical activity. Champaign (Illinois): Human Kinetics.

McMorris, T. (1999). Cognitive development and the acquisition of decision-making skills. International Journal of Sport Psychology, 30, 151-172.

McMorris, T., Sproule, J., Macgillivary, W. W., \& Lomax, J. (2006). Cognitive development and performance of 11-, 13- and 15-year olds on a soccerspecific test of decision making. International Journal of Sport and Exercise Psychology, 4(2), 170-181. Doi:10.1080/1612197x.2006.9671791

McPherson, S. L. (1993). The influence of player experience on problem solving during batting preparation in baseball. Journal of Sport \& Exercise Psychology, 15, 304-325.

Micklewright, D., Angus, C., Suddaby, J., Gibson, A. S., Sandercock, G., \& Chinnasamy, C. (2012). Pacing Strategy in Schoolchildren Differs with Age and Cognitive Development. Medicine \& Science in
Sports $\& \quad$ Exercise, 44(2), 362-369.

Doi: $10.1249 / \mathrm{mss} .0 \mathrm{~b} 013 \mathrm{e} 31822 \mathrm{cc} 9 \mathrm{ec}$

Middleton, T. (2016) Regulating Pre-performance Psychobiosocial States with Music. (n.d.). Thesis for: Masters of Sport Science - European Masters of Sport and Exercise Psychology, DOI: 10.13140/RG.2.1.3011.9922

Oaten, M., \& Cheng, K. (2006). Longitudinal gains in self-regulation from regular physical exercise. British Journal of Health Psychology,11(4), 717-733. Doi:10.1348/135910706x96481

Piero, L. B., Saxbe, D. E., \& Margolin, G. (2016). Basic emotion processing and the adolescent brain: Task demands, analytic approaches, and trajectories of changes. Developmental Cognitive Neuroscience,19, 174-189. Doi:10.1016/j.dcn.2016.03.005

Reeves, C. W., Nicholls, A. R., \& Mckenna, J. (2009). Stressors and Coping Strategies among Early and Middle Adolescent Premier League Academy Soccer Players: Differences According to Age. Journal of Applied Sport Psychology, 21(1), 31-48. Doi:10.1080/10413200802443768

Robazza, C., Bertollo, M., Ruiz, M. C., \& Bortoli, L. (2016). Measuring Psychobiosocial States in Sport: Initial Validation of a Trait Measure. Plos One, 11 (12). Doi:10.1371/journal.pone.0167448

Ruiz MC, Hanin YL, Robazza C. Assessment of performance-related experiences: An individualized approach. Sport Psychol. Forthcoming 2016.

Ruiz, M. C., Raglin, J. S., \& Hanin, Y. L. (2017). Individual zones of optimal functioning (IZOF) model (1878-2014): Historical overview of its development and use. International Journal of Sport and Exercise Psychology. Doi: 10.1080/1612197X.2015.1041545

Stang J and Story M (eds), Guidelines for Adolescent Nutrition Services (2005), retrieved on 30 th June, 2014 from http://www.epi.umn.edu /let/pubs/adol_book.shtm.

Starkes, J. L., Allard, F., Lindley, S., \& O’Reilly, K. (1994). Abilities and skill in basket- ball. International Journal of Sport Psychology, 25, 249-265.

Tiwari, L. M., Rai, V., \& Srinet, S. (2011). Relationship of Selected Motor Fitness components with the Performance of Badminton Player Asian 
Journal of Physical Education and Computer Science in Sports, 5(1), 88-91.

Touron, D. R., \& Hertzog, C. (2004). Distinguishing Age Differences in Knowledge, Strategy Use, and Confidence During Strategic Skill Acquisition. Psychology and Aging, 19(3), 452-466. http://dx.Doi.org/10.1037/0882-7974.19.3.452

Weiss, M. R., Amorose, A. J., \& Wilko, A. M. (2009). Coaching Behaviors, Motivational Climate, and Psychosocial Outcomes among Female Adolescent Athletes. Pediatric Exercise Science, 21 (4), 475-492. Doi:10.1123/pes.21.4.475

Zald, D. H. (2003). The human amygdala and the emotional evaluation of sensory stimuli. Brain Research Reviews, 41(1), 88-123. Doi:10.1016/s01650173(02)00248-5

Zemková, E., \& Hamar, D. (2018). Sport-Specific Assessment of the Effectiveness of Neuromuscular Training in Young Athletes. Frontiers in Physiology,9. Doi:10.3389/fphys.2018.00264
Zimmerman, B. J. (1989). A social cognitive view of self-regulated academic learning. Journal of Educational Psychology, 81, 329-339.

Zimmerman, B. J. (1998). Academic studying and the development of personal skill: A self-regulatory perspective. Educational Psychologist, 33, 73-86.

Zimmerman B. J. (2000). "Attaining selfregulation: a social cognitive perspective". In Boekaerts M., Pintrich P. R. \& Zeidner M. (Eds.). Handbook of Self-Regulation (pp. 13-40). San Diego, CA: Academic Press. Doi: 10.1016/b978-0121098902/50031-7 